\title{
Coupling and quantifying resilience and sustainability in facilities management
}

\author{
Cox, Rimante Andrasiunaite; Nielsen, Susanne Balslev; Rode, Carsten
}

Published in:

Journal of Facilities Management

Link to article, DOI:

10.1108/JFM-04-2015-0012

Publication date:

2015

Document Version

Peer reviewed version

Link back to DTU Orbit

Citation (APA):

Cox, R. A., Nielsen, S. B., \& Rode, C. (2015). Coupling and quantifying resilience and sustainability in facilities management. Journal of Facilities Management, 13(4), 314-331. https://doi.org/10.1108/JFM-04-2015-0012

\section{General rights}

Copyright and moral rights for the publications made accessible in the public portal are retained by the authors and/or other copyright owners and it is a condition of accessing publications that users recognise and abide by the legal requirements associated with these rights.

- Users may download and print one copy of any publication from the public portal for the purpose of private study or research.

- You may not further distribute the material or use it for any profit-making activity or commercial gain

- You may freely distribute the URL identifying the publication in the public portal

If you believe that this document breaches copyright please contact us providing details, and we will remove access to the work immediately and investigate your claim 


\section{Emerald $\begin{aligned} & \text { Journal of Facilities } \\ & \text { Management }\end{aligned}$}

\section{Coupling and quantifying resilience and sustainability in facilities management}

\begin{tabular}{|r|l|}
\hline Journal: & Journal of Facilities Management \\
\hline Manuscript ID: & JFM-04-2015-0012.R1 \\
\hline Manuscript Type: & Research Paper \\
\hline Keywords: & $\begin{array}{l}\text { Building's resilience, sustainability, climate adaptation, risk analysis, } \\
\text { facilities management, climate adaptation }\end{array}$ \\
\hline \multicolumn{2}{|l}{} \\
\hline
\end{tabular}

SCHOLARONE ${ }^{\text {m }}$

Manuscripts 


\section{COUPLING AND QUANTIFYING RESILIENCE AND SUSTAINABILITY IN FACILITIES MANAGEMENT}

\section{INTRODUCTION}

A building's resilience is a measure of how well a building continues to function, e.g. internal cooling during and after an event e.g. heat wave, and if the function has been affected, how fast the building regains function. Resilience can be very important. The consequences of loss of function of a building can be very serious, resulting not just in large financial losses, but even in loss of life Ballester et al. (1997). It is increasingly clear, however, that the way a particular function of a building is provisioned may have significant repercussions well beyond those of resilience. For example, customers increasingly care about how a product or service is provided, and not just the product or service itself. Provisioning a building function must therefore consider not just the resulting resilience but also the resulting sustainability, where sustainability broadly refers to social, environmental and financial repercussions.

This paper considers resilience and sustainability of a building in the context of climate change. Climate resilience of buildings has received a significant interest Biesbroek (2010), Bosher et al. (2007) Camilleri et al. (2001) due to predictions that climate change will cause more extreme weather events Beniston et al. (2007). Climate adaptation and resilience are no longer just political issues but are also emerging topics in facilities management (FM) research (e.g Warren (2010) and Jones (2014).

At a practitioner level, most maintenance and operation strategies do not yet deal with climate change and sustainability, beyond simple energy savings, the latter being tied to cost reductions and compliance with current building regulation. One reason for this may be a lack of management tools to support calculations of costs and benefits in an integrated manner, as pointed out e.g. by Oeyen et al. (2009). New decision support tools are needed to support new building designs and renovations that consider resilience and sustainability in an integrated manner. The intention of this research is to fill the gap between the need for increasing sustainability and resilience of the built environment and the current practices in facilities management.

Numerous methods have been proposed for measuring both resilience and sustainability, separately. Further, many definitions of resilience and/or sustainability are difficult to quantify and as such provide insufficient information with which to make investment decisions. Since, almost all investment decisions are determined by economic models such as return of investment, we believe that quantifying, in a monetary sense, resilience and sustainability is necessary. Currently there is no generally agreed understanding of how to couple resilience and sustainability.

Our proposal to couple resilience and sustainability for buildings is motivated by a need to provide decision support tools to facilities managers, who are responsible for property maintenance. To do so, we assume an economist's perspective that facility managers base their decisions on economic criteria, i.e. facility managers are asked to create as much value as possible out of a given budget. Under this assumption, it is imperative that costs be associated 
with resilience and sustainability. To address this issue we show how risk management tools, familiar to some building owners, facility managers, architects, and other decision makers, can be used to quantify resilience and sustainability, and facilitate the decision process for selecting between remedial solutions with varying degrees of sustainability.

The paper has the following structure. In Section 2, we first review previous work on resilience and how risk management can and has been used to quantify resilience. Ultimately we see resilience and risk as two sides of the same coin: the higher the risk, the less resilient a building is. In a similar way we review sustainability and methods to quantify it, and then review the literature on coupling resilience and sustainability. In Section 3 we discuss how sustainable solutions can be incorporated into the risk framework through economic concepts that quantify the loss of function (resilience) and cost of environmental damage and loss of reputation (sustainability). Then we describe our proposed method for Coupling and Quantifying Resilience and Sustainability (CQRS). Section 4 provides an illustrative example of how the CQRS method can be used. Finally, Section 5 provides a discussion of the method, and Section 6 concludes and suggests directions for future work.

\section{BACKGROUND}

Section 2.1 reviews prior work on resilience. Resilience is increasingly used in the context of climate change and climate adaptation of the built environment. Most studies of resilience to climate change have been undertaken by (i) mapping threats such as the increased possibility of flooding, sea level rise or heat-waves Beniston et al. (2007), Biesbroek (2010), Bosher et al. (2007), de Wilde et al. (2011), Snow et al. (2011), Jones (2014), (ii) investigating the vulnerability of a system to these threats Guan (2012), Camilleri et al. (2001), Jentsch et al. (2008), and (iii) investigating how to adapt Lomas (2009). Section 2.2 then briefly outlines how a risk framework Faber (2012) can we used to economically quantify resilience. Section 2.3 reviews prior work on sustainability and Section 2.4 proposes how to couple resilience and sustainable within a risk framework that can be expressed in monetary terms.

\subsection{Definition of Resilience}

A number of studies exploring the definition of resilience in different contexts have been recently undertaken, including Hassler et al. (2014), Vale (2014), Tainter et al (2014), and Anderies (2014). Bosher (2014) distinguishes four categories of resilience, specifically (i) resistance/robustness/absorptions; (ii) recovery/“bouncing back" (iii) planning/preparing/protecting, (iv) adaptive capacity. In this paper we focus on planning/preparing/protecting, as we investigate how to improve resilience in an existing building during planned maintenance work.

Resilience seeks to determine how well a building or system continues to function during and after the event. As such, we broadly follow the definition of Nelson et al. that "System resilience refers to the amount of change a system can undergo and still retain the same controls on function and structure ..." Nelson et al. (2007), although we acknowledge a number of other possible definitions of resilience depending on various perspectives. Manyena (2006), Folke et al. (2002), Bosher et al. (2007), Carpenter et al. (2001), Holling (1996), Pimm et al. (1984). 
Carpenter et al. (2001) highlighted the importance of specifying "Resilience of What to What", which reflects the practitioners' need for practical methods to quantify resilience. In this paper we focus on resilience to extreme weather events such as heat wave, although the framework is applicable to other events as well. Holling (1996) defines resilience as the magnitude of a disturbance, e.g. temperature that a system can tolerate and still remain in a desired state. Thus, we might say that a building is resilient to average daily temperatures of up to $\mathrm{T}$ degrees. A contrasting definition by Pimm et al. (1984) defines resilience as that rate at which a system returns to its desired state after a disturbance. Thus, under Pimm et al.'s definition, a building may lose functionality for some period before becoming operational again. The shorter this period of lost functionality, the higher the rate of return to the desired state, and thus the higher a building's resilience is. While we acknowledge that the rate of recovery is important, we do not explicitly consider this in our subsequent work. Rather, for simplicity, we rely on the definition of Nelson, previously given and define resilience as such: "A building's resilience is a measure of how well a building continues to function, e.g. internal cooling during and after an event e.g. heat wave, and if the function has been affected, how fast the building regains the function".

While such measures of resilience are valuable, we believe such measures are of limited value in supporting the process of deciding whether remedial action should be taken to improve a building's resilience. For example, knowing that a building is resilient to average daily temperatures of up, to say $32^{\circ} \mathrm{C}$, is useful, but any investment decision must also consider both the cost of failure when daily temperatures exceed $32^{\circ} \mathrm{C}$ and the probability of such weather events occurring. The latter probability is necessary to arrive at an overall expected cost that can be directly used to prioritize investments. Assigning an economic cost to resilience can be handled using well-known risk measures, as discussed next.

\subsection{Quantification of expected cost associated with a level of resilience}

The cost associated with a particular resilience can be measured using risk analysis. The risk $(R)$ is defined as the expected monetary cost associated with a given activity Faber (2012) as shown in equation [1]. Risk can be described by a function of the probability $\left(P_{f}\right)$ of a failure event, $f$, occurring, together with the corresponding consequence $\left(C_{f}\right)$ of failure, measured in monetary units. If there are $n$ possible events, then the risk is defined as

$$
R_{f}=\sum_{f=1}^{n} P_{f} * C_{f}
$$

(1)

From the facilities management prespective there are several advantages to using risk assessment to quantify resilience. First, risk analysis requires facilities managers to clearly define resilience of what to what. Thus, to quantify the resilience of a building, we need to split the building system into different problem areas: for example if we are investigating the resilience to overheating we need consider only the indoor environment for example temperature and not other parameters such as degradation of the external materials. Second, by calculating the risk of failure it is possible to express the failure in monetary terms. Knowledge of this cost allows a facilities manager to determine whether there is a cost effective solution to improve resilience. This is often accomplished using well known methods such as cost benefit analysis (CBA). CBA 
is a well-respected tool where everything is converted into monetary terms and decisions are based on highest net value Ding (2008).

We note that Jones, who proposed to identify climate change threats using future weather files and suggested methods to improve the resilience of a building to such threats quantified the resilience using risk assessment. However, the method does not explicitly include sustainability Jones (2014).

A limitation of resilience is that it only considers the cost associated with the loss of function of the building. However, it is increasingly recognized that a building's systems can and do have other associated costs, particularly environmental and reputational that indirectly affect the financial viability of a company. We see the concept of sustainability as addressing these other costs.

\subsection{Definition of sustainability}

A definition of sustainable development (SD) was formulated by the Brundtland Commission in 1987 as "development that meets the needs of the present without compromising the ability of future generations". This definition is often described as triple bottom line, because it considers environmental, economic and social consequences of development. According to this definition the environmental, social and economic needs are defined as equal and "must deliver prosperity, environmental quality and social justice” Ding (2008).

However, the Brundtland Commission definition is not well understood. For example, Dettwiler argues that definitions of sustainability and sustainable development are used in too many different contexts and have many different meanings without a clear consensus Detwiller (2014). Bossel argues that the definition of sustainability as "maintaining a system" cannot be used literally, as "human society is a complex and adaptive system and is embedded in a natural environment system, and both systems continuously change" Bossel (1999). Bossel argues that the ability for change and evolution must be maintained if human society is to be able to cope with a changing environment. Baxter et al. suggested "sustainability is the ability of our own human society to continue indefinitely within natural cycles of the earth" Baxter et al. (2010).

In the context of the built environment, sustainability has been widely used to refer to methods of reducing the environmental impact of buildings. Thus, it is not required that a building be completely sustainable, i.e. will have no impact on the environment. Rather, sustainability is interpreted as a measure of the relative reduction in environmental impact compared to a baseline, such as the environmental impact of a building that only just satisfies associated building standards.

A number of methods have been developed to assess the environmental impact of a building. These include different sustainability indicators covering all 3 aspects of sustainability (environmental, economic and social). Typically, sustainability indicators vary, are specific to a particular project Bossel (1999), and are more useful for larger systems such as organisations, communities or countries. The disadvantage of the method is that it is very generic and difficult to apply to a single building. For that purpose, different environmental assessment tools have been developed to evaluate the overall environmental impact of buildings such as (i) Building Research Establishment Environmental Assessment Methodology (BREEAM), established in UK in 1990 by the Building Research Establishment and most wildly used environmental assessment methodology in the world, (ii) Leadership in Energy \& Environmental Design 
(LEED) developed by Green Building Council launched in 1993 in US and also world wild used (iii) or Germen environmental assessment tool developed by Deutsche Gesellschaft für Nachhaltiges Bauen (DGNB) in 2007, which is the newest environmental assessment tool and most popular in Europe. These tools as well as other less known environmental assessment tools are usually based on awarded points, which are weighted to estimate the overall environmental impact of the building. The advantage of such methods, e.g. BREEAM, LEED, DGNB is that the environmental performance of buildings becomes more comparable within the same method and within similar geographic regions Cole (1998). A disadvantage of point-based methods is that they do not explicitly consider economic cost nor resilience.

Quantifying sustainability in monetary terms was considered by Ding (2008) in the context of the construction industry. Ding proposed a sustainability index where different alternative solutions can be calculated and compared to each other by including not only the economic cost of a solution but also the benefit cost ratio, energy consumption, external benefits and environmental impact. The method takes into account absolute quantities of resources and energy flows during the whole lifetime of the building and includes embodied and operational energy. The method expresses sustainability of the solution in monetary terms, and, as such, has some similarity with our proposal. However, the method does not consider the resilience of the solution and it is not clear how resilience could be integrated into their proposal. Furthermore, the methodology is not based on a risk framework.

\subsection{Integrating resilience and sustainability}

The idea of merging both sustainability as a mitigation option and resilience as an adaptation option has been suggested by Mills (2003), Bosher et al. (2007) and, Folke et al. (2002). Bosher defines "built in resilience" for a built environment that considers sustainability as "should be designed, located, built, operated and maintained in a way that maximises the ability of built assets, associated support systems (physical and institutional) and the people that reside or work within the built assets, to withstand, recover from, and mitigate for, the impacts of extreme natural hazards and human-induced threats" Bosher (2014). To identify the risk associated with failure of energy systems and its impact on the environment was proposed by McLellan et al. (2012). McLellan et al.'s and Bosher et al.'s proposals highlight the connection between sustainability and resilience, but do not suggest how to quantify the cost.

The first attempt to quantify sustainability and resilience was by Camilleri et al. who proposed the Climate Change Sustainability Index Camilleri et al. (2001). The method proposed by Camilleri et al. is designed to both (i) rate the impact of climate change on a building, in order to identify the most vulnerable buildings, and (ii) to assess the impact of the building on the environment. The method consists of two separate numeric ratings: one for impact on buildings and another for greenhouse gas emissions, the latter being a measure of environmental sustainability. Camilleri et al. uses a risk assessment to identify the most significant climate change threats on buildings and quantify the vulnerability of the buildings to these threats. The method addresses both concepts separately, but does not couple resilience and sustainability. The idea of coupling both resilience and sustainability was briefly discussed in Cox et al. (2014), but the article did not propose how to couple and quantify resilience and sustainability.

The next Section considers how to couple resilience and sustainability. 


\section{METHODOLOGY}

Based on the literature review above, in Section 3.1 we explain the purpose of coupling resilience and sustainability. In section 3.2 we describe how to couple and quantify both using a well known risk management tool, and in section 3.3 we propose the conceptual method of Coupling and Quantifying Resilience and Sustainability (CQRS).

\subsection{Coupling resilience and sustainability}

To couple resilience and sustainability, we propose determining the expected cost (risk) to a company of providing a function of a building in a particular manner, where the cost considers functional (resilience), as well as environmental, economic and possibly social dimensions (sustainability).

This is very different from resilience alone. Consider, for example, the function of cooling a building. Resilience only considers under what conditions the cooling system will fail, and the expected cost associated with resilience is only due to the costs associated with a loss of function. If there is no loss of function, resilience is perfect and there is no expected cost. In contrast, resilience and sustainability considers not only the cost associated with loss of function, but also costs associated with environmental sustainability and economic sustainability. Thus, the expected cost associated with resilience and sustainability of, say cooling, may be high, even when there is no loss of functionality, if providing this function has environmental, economic or social repercussions.

\subsection{Quantifying resilience and sustainability}

In order to meet the expressed need of measuring and quantifying engineering solutions and to allow multi-criteria comparisons of alternative solutions we integrate both the risks associated with resilience and sustainability to derive the expected cost, in monetary terms. The expected cost explicitly includes environmental, economic and social costs that are incurred by provisioning a function of a building in a particular way.

Since we assume an economist's perspective that facility managers are rational and base decisions on economic criteria, it is imperative that a monetary cost be associated with sustainability, or the lack thereof. Such costs can be either direct or indirect costs. For example, the carbon output of a building may have a direct cost if a carbon tax is imposed. Alternatively, the carbon output of a building may have an indirect cost in the absence of a carbon tax. This indirect cost may manifest itself as a reputational cost that must be determined based on a company's public appearance. A company that promotes itself as "green" may suffer significant reputational loss if it is found to be a major polluter of greenhouse gases. This loss in reputation will have a financial impact on its revenues. Clearly the cost due to loss of reputation is nondeterministic, and even direct costs such as carbon taxes may vary over time. However, once again risk can be used to determine the expected cost.

Based on the Brundtland Commission's definition, sustainability has three key dimensions, environmental, economic, and social. We can quantify each dimension separately using a risk framework, to determine the environmental risk, $R_{e}$, economic/business risk, $R_{b}$, and social risk, $R_{s}$. 
Thus, environmental damage may be estimated as environmental risk $R_{e}$ with associated probability $P_{e}$ of environmental cost $C_{\mathrm{e}}$, due to a number of $m$ events as shown in equation [2]. Some of these costs are referred to as externalities within economics such as: environmental taxes, carbon costs, water consumption, etc.

$$
R_{e}=\sum_{e=1}^{m} P_{e} * C_{e}
$$

(2)

Similarly, the expected cost for economic/business sustainability $R_{b}$ is expressed in equation [3]

$$
R_{b}=\sum_{b=1}^{l} P_{b} * C_{b}
$$

(3)

where $l$ is the number of event associated with economic sustainability, e.g. reputational risk, $P_{b}$ the probability of the cost to occur, and $C_{b}$ the cost of loss of reputation.

The expected cost for social sustainability $R_{s}$ can be determined similarly in equation [4].

$$
R_{S}=\sum_{s=1}^{k} P_{S} * C_{s}
$$

(4)

where $k$ is the number of events associated with social sustainability, e.g. loss of employment, $P_{s}$ the probability of such event to occur, and $C_{s}$ the cost associated with such event .

The expected cost associated with resilience and sustainability is simply the sum of the expected functional, environmental, economic and social costs as shown in equation [5]. That is,

$$
R_{r s}=\sum_{f=1}^{n} P_{f} * C_{f}+\sum_{e=1}^{m} P_{e} * C_{e}+\sum_{b=1}^{l} P_{b} * C_{b}+\sum_{s=1}^{k} P_{s} * C_{s}
$$


(5)

where the first summation measures the functional cost, i.e. the cost associated with loss of function of the building, the second summation measures environmental cost, the third economic cost and the fourth social cost.

Thus, resilience, together with a risk analysis, helps to identify what improvements are required of a building. Resilience coupled with sustainability helps identify how changes in resilience are provided, based on explicit modelling of environmental, economic and social costs.

\subsection{The conceptual method of Coupling and Quantifying Resilience and Sustainability}

The CQRS method is primarily theoretical. The conceptual study draws on current literature on sustainability and resilience to propose how they should be coupled.

The CQRS method consists of seven steps:

1. Determine the resilience of the building to the disturbance(s), i.e. at what temperature will the building's functions be compromised.

2. Determine the costs associated with both the loss of building functionality and the building's current sustainability.

3. Determine the corresponding probabilities associated with each cost.

4. Determine the expected cost associated with the current resilience and current sustainability of the building using risk analysis.

5. Determine capital and operational costs of each remedial solution.

6. For each remedial solution, determine the expected cost associated with the proposed resilience and proposed sustainability of the building using risk analysis.

7. Select (or not) a solution based on cost benefit analysis.

We use an example of an small office building to illustrate the methodology and its valuation of two alternative solutions on a maintenance problem. In the example we follow Baxter's definition of sustainability where the proposed sustainable solution e.g. upgrading the air conditioning system, is the solution where the electricity used for the system is provided by the locally installed PV system.

\section{A ILLUSTRATIVE EXAMPLE}

Consider the hypothetical architectural company, Green, Greener and Greenest (GG\&G), which specializes in the design and refurbishment of environmentally sustainable buildings. The offices of GG\&G are located in an urban environment and consist of a single, detached, 3-storey building originally constructed in the 1920s. The building provides office space for 30 employees. It is centrally heated and has a small central air conditioning unit. In the previous year, GG\&G experienced a number of days where the building was uncomfortably hot, due to an unusually warm summer period. During this period, the air conditioning system was not capable of sufficiently cooling the building. The company lost 100 person-hours. As a result of this, the company decided to investigate their sustainable resilience to heat waves. GG\&G followed the 7step process outlined above.

1. Determine the resilience of the building to the disturbance(s), i.e. at what temperature will the building's functions be compromised. 
GG\&G determined, based on a dynamic simulation model of their building, that the interior temperature will exceed $26^{\circ} \mathrm{C}$ when the exterior temperature exceeds $28^{\circ} \mathrm{C}$. The central air conditional cooling unit is responsible for $8.4 \mathrm{t} /$ year $\mathrm{CO}_{2}$ emissions.

2. Determine the costs associated with both the loss of building functionality and the building's current sustainability.

For simplicity, we only consider three types of associated costs: (i) failure costs, (ii) environmental costs, and (iii) economic costs. We do not consider social costs, but these can, in principle, be included.

\subsection{Failure costs}

When the building's interior temperature exceeds $26^{\circ} \mathrm{C}, \mathrm{GG} \& \mathrm{G}$ estimated that productivity will drop by $5 \%$, resulting in a loss of $\$ 150$ per hour per person. Column 2 in Table 1 summaries the cost of loss of function due to loss of productivity for each of $n$ periods, where $n$ is a number of hours above $26^{\circ} \mathrm{C}$ occurring during a one year period. In addition, GG\&G estimated that the air conditioning system consumed $\$ 0.36$ per hour to operate and used $10,000 \mathrm{kWh}$ for cooling a year.

\subsection{Environmental costs}

GG\&G assumed that the environmental costs are mainly due to $\mathrm{CO}_{2}$ emissions generated as a by-product of electricity consumption. The company consumes $10,000 \mathrm{kWh}$ a year for cooling. It is further assumed that this environmental cost may result in a carbon tax on the company. It is further assumed that the electricity produces $0.84 \mathrm{~kg} \mathrm{CO}_{2} / \mathrm{kWh}$. While there is currently no such tax, GG\&G expects a carbon tax to be introduced in the near future. For simplicity, the probability of a carbon tax is assumed to be linearly increasing during the 5 -year period of interest, with a probability of 0 currently and a probability of 1 at year 5. The tax is assumed to be \$50/tonne (Luckow P., 2014) and, for simplicity, is assumed constant over the 5-year period. Column 2 in Table 2 shows the cost associated with environmental sustainability. We assumed that the cost of carbon is the same for all 5 years.

\subsection{Economic cost}

GG\&G assumed that the main economic cost would be due to loss of reputation. Loss of reputation is assumed to cost $10 \%$ of revenue, i.e. $\$ 1,000,000$. For simplicity, GG\&G further assumed that once the reputational cost was incurred, it would persist for the remainder of the 5-year period, i.e. if loss of reputation occurred in year $i$, then the total cost is $\$(5-i) * 1,000,000$.

Column 2 in Table 3 below shows the cost associated with economic sustainability during the 5 years period.

3. Determine the corresponding probabilities associated with each cost.

We now consider the associated probabilities. We consider the probabilities associated with each of the functional, environmental and reputational losses in turn.

\subsection{Functional probabilities}

To determine the expected cost, we also need the probability, $P_{f}(n)$, that the temperature 
will exceed $26^{\circ} \mathrm{C}$, for $n$ hours. For simplicity, we assume $P_{f}(n)$ has a Gaussian distribution with a mean, $\mu=100$, and a variance $\sigma$ of 3 , where $n$ is the number of hours above $26^{\circ} \mathrm{C}$. Thus $P_{f}(n)$ is given by equation 6 .

$$
\left.P_{f}(n)\right)=\frac{1}{\sigma * \sqrt{2 \pi}} e^{-\frac{(n-\mu)^{2}}{2 \sigma^{2}}}
$$

(6)

For simplicity, we chose to only consider $90<n<110$, as values outside this range have very small probability and do not significantly affect the cost. Column 3 of Table 1 enumerates the probabilities over this range. 


\begin{tabular}{|c|c|c|c|}
\hline $\begin{array}{c}\text { Number of hours above } \\
26^{\circ} \mathrm{C} \\
n\end{array}$ & $\begin{array}{c}\text { Cost of loss } \\
\text { of function } \\
C_{f} \\
\end{array}$ & $\begin{array}{c}\text { Probability of loss of } \\
\text { function } \\
P_{f}\end{array}$ & $\begin{array}{c}\text { Expected cost of loss of } \\
\text { function } \\
R_{f} \\
\end{array}$ \\
\hline 109 & 24,525 & 0.0015 & 36 \\
\hline 108 & 24,300 & 0.0038 & 92 \\
\hline 107 & 24,075 & 0.0087 & 210 \\
\hline 106 & 23,850 & 0.0180 & 429 \\
\hline 105 & 23,625 & 0.0332 & 784 \\
\hline 104 & 23,400 & 0.0547 & 1,280 \\
\hline 103 & 23,175 & 0.0807 & 1,870 \\
\hline 102 & 22,950 & 0.1065 & 2,444 \\
\hline 101 & 22,725 & 0.1258 & 2,859 \\
\hline 100 & 22,500 & 0.1330 & 2,993 \\
\hline 99 & 22,275 & 0.1258 & 2,803 \\
\hline 98 & 22,050 & 0.1065 & 2,349 \\
\hline 97 & 21,825 & 0.0807 & 1,761 \\
\hline 96 & 21,600 & 0.0547 & 1,181 \\
\hline 95 & 21,375 & 0.0332 & 709 \\
\hline 94 & 21,150 & 0.0180 & 381 \\
\hline 93 & 20,925 & 0.0087 & 183 \\
\hline 92 & 20,700 & 0.0038 & 79 \\
\hline 91 & 20,475 & 0.0015 & 30 \\
\hline Total & & & 22,473 \\
\hline
\end{tabular}

Table 1 Cost of loss of function in a year

3.2. Environmental probabilities

GG\&G assume that the probability of a carbon tax is linearly increasing from zero in the current year to 1 in year 5 . Thus the probability of a carbon tax in year $y$ is shown in the equation 7 .

$$
P_{e}(y)=\frac{(y-1)}{4}
$$

where $1<=y<=5$. Column 3 of Table 2 enumerates these probabilities. 


\begin{tabular}{cccc}
\hline Number of years $\boldsymbol{n}$ & Cost $\boldsymbol{C}_{\boldsymbol{e}}$ & Probability $\boldsymbol{P}_{\boldsymbol{e}}$ & Expected cost $\boldsymbol{R}_{\boldsymbol{e}}$ \\
\hline $\boldsymbol{0}$ & 420 & 0 & 0 \\
$\mathbf{1}$ & 420 & 0.2 & 84 \\
$\mathbf{2}$ & 420 & 0.4 & 168 \\
$\mathbf{3}$ & 420 & 0.6 & 252 \\
$\mathbf{4}$ & 420 & 0.8 & 336 \\
$\mathbf{5}$ & 420 & 1 & 420 \\
Total & & & $\mathbf{1 , 2 6 0}$ \\
\hline
\end{tabular}

Table 2 Cost of loss due environmental cost, carbon taxes in 5 years

\subsection{Economic probabilities}

GG\&G assumed that the probability of loss of reputation $P_{b}$ in any one year is constant and equal to 0.1 . Since GG\&G assume that a loss of reputation in year $l$ persists for the remaining years, then the probability of the loss of reputation occurring in year $y$, is the product of the probability of the loss not occurring in the preceding $(l-1)$ years times the probability of the loss of reputation occurring in year $l$. Thus, the probability $P_{l}(1)$ of a loss of reputation in year 1 is simply 0.1 . The probability of a loss of reputation in year 2 is the probability of no loss of reputation in year 1 times the probability of a loss of reputation in year 2 , i.e. in equation 8 .

$$
P_{b}(2)=(1-0.1) * 0.1=0.09
$$

(8)

In general, the probability in year $l$ is shown in equation [9] and is

$$
P_{b}(l)=(1-0.1)^{(l-1)} 0.1
$$

(9)

Column 3 of Table 3 enumerates the probabilities of loss of reputation in every year.

\begin{tabular}{cccc}
\hline $\begin{array}{c}\text { Numbers of } \\
\text { years } \boldsymbol{I}\end{array}$ & $\begin{array}{c}\text { Economic reputational } \\
\text { cost } \boldsymbol{C}_{\boldsymbol{b}}\end{array}$ & Economic Probability $\boldsymbol{P}_{\boldsymbol{b}}$ & Expected Economic cost $\boldsymbol{R}_{b}$ \\
\hline $\mathbf{1}$ & 500,000 & 0.1000 & 50,000 \\
$\mathbf{2}$ & 400,000 & 0.0900 & 36,000 \\
$\mathbf{3}$ & 300,000 & 0.0810 & 24,300 \\
$\mathbf{4}$ & 200,000 & 0.0729 & 14,580 \\
5 & 100,000 & 0.0656 & 6,561 \\
\hline Total & & & 131,441 \\
\hline
\end{tabular}

Table 3: The cost due to loss of reputation over a 5 year period. 
4. Determine the expected cost associated with the current sustainable resilience of the building using risk analysis.

Steps 1-3 provide the basis for calculating the expected cost. We consider the expected functional, environmental and economic costs in turn.

\subsection{Expected functional costs}

The expected costs, $R_{f}$, due to loss of function is given by equation [10]

$$
R_{f}=\sum_{y=1}^{5} \sum_{n=100-3 \sigma}^{100+3 \sigma} P_{f}(n) C_{f}(n)=5 \sum_{91}^{109} P_{f}(n) C_{f}(n)
$$

(10)

where $n$ is the number of hours above $26^{\circ} \mathrm{C}$ occurring during a year period .

Column 4 of Table 2 shows the calculation of annual expected costs for the loss of function. The expected cost due to loss of function over a 5 year period is $22,473 \times 5$. Thus

$R_{f}=\$ 112,000$.

\subsection{Expected environmental costs}

The expected costs, $R_{e}$, due to environmental issues is given by equation [11]

$$
R_{e}=\sum_{m=1}^{5} P_{e}(y) C_{e}
$$

(11)

From column 4 in Table 2 we see that the expected environmental costs over the 5-year period is $\$ 1,260$.

\subsection{Expected economic cost (loss of reputational)}

The expected costs, $R_{b}$ due to loss of reputation is shown in equation [12]

$$
R_{b}=\sum_{l=1}^{5}(1-0.1)^{(l-1)} 0.1 C_{b}(l)
$$

(12)

From column 4 in Table 3 we see that the expected reputational cost over the 5 -year period is $\$ 131,000$.

\subsection{Total expected cost}

The total expected cost, $\mathrm{R}_{\mathrm{rs}}$, associated with the current resilience and sustainability of 
the building is simply the sum of these individual costs, i.e as shown in equation [13]

$$
R_{r s}=\sum_{f=1}^{n} P_{f}(n) C_{f}(n)+\sum_{e=1}^{m} P_{e}(y) C_{e}+\sum_{b=1}^{k} P_{b}(k) C_{b}(k)
$$

(13)

The expected cost of resilience (loss of function) over the 5-year period is $\$ 112,000$.

The expected cost of environmental sustainability (carbon taxes) over the 5-year period is $\$ 1,260$.

The expected cost of economic sustainability (reputation) over the 5-year period is $\$ 131,000$.

The operational cost due to electricity consumption over 5 years period is $\$ 18,000$

The total expected cost for the company for not upgrading the system is therefore $\$ 263,000$.

Note that the expected cost when only considering resilience is $\$ 130,000$.

5. Determine capital and operational costs of each remedial solution GG\&G considered two remedial solutions.

5.1. Solution 1 upgrades the air conditioning system. The capital cost is $\$ 100,000$. The new system consumes $12,000 \mathrm{kWh}$. The annual running cost is estimated to be $\$ 4,320$. The new air conditioner completely eliminates the risk of loss of function. The capital and operational cost for Solution 1 is $\$ 122,000$, during the 5-year period, when only resilience of the building is considered, as shown in Column 3 in Table 4.

5.2. Solution 2 upgrades the air conditioning system and adds onsite photovoltaic electricity generation. While the new system consumes $12,000 \mathrm{kWh}$, all this energy is provided through the onsite photovoltaic system. The capital and operational cost is $\$ 100,000+\$ 30,000+\$ 0$ $=\$ 130,000$, as shown in Column 4 in Table 4 . 


\begin{tabular}{lccc}
\hline $\begin{array}{l}\text { Traditional Cost Benefit } \\
\text { Method }\end{array}$ & Existing & Cost of Solution 1 & Cost of solution 2 \\
\hline & $\mathbf{\$}$ & $\mathbf{\$}$ & $\mathbf{\$}$ \\
\hline Cost of failure & 112,000 & 0 & 0 \\
Running cost of a/c & 18,000 & 21,600 & 0 \\
\hline Capital cost of a/c & 0 & 100,000 & 100,000 \\
Capital cost of PV & 0 & 0 & 30,000 \\
\hline Total & $\mathbf{1 3 0 , 0 0 0}$ & $\mathbf{1 2 1 , 6 0 0}$ & $\mathbf{1 3 0 , 0 0 0}$ \\
\hline
\end{tabular}

Table 4 Expected cost for the company over 5 -year period when only resilience is considered.

6. For each remedial solution determine the expected cost associated with the proposed resilience and proposed sustainability of the building using risk analysis.

6.1. The capital and operational cost for Solution 1 for 5 years is $\$ 122,000$. However, the risk from environmental issues increases from $\$ 1,260$ to $\$ 1,510$. Moreover, the probability of loss of reputation is assumed to increase from $10 \%$ to $15 \%$ of revenue due to the increased output of greenhouse gases. Thus the expected reputational cost increases from $\$ 131,000$ to $\$ 185,000$. The total expected cost over the 5-year period is then $\$$

6.2. 308,000, as shown in Column 3 in Table 5. Note that this expected cost is actually higher than the expected cost for not upgrading the system, despite the fact that the risk of loss of function was eliminated.

6.3. The capital and operational cost for Solution 2 is $\$ 130,000$. Consequently, all three risks, function, environment and reputation, are eliminated. Then the total expected cost of the solution 2 for 5 years period is only the capital cost which is $\$ 130,000$, as shown in Column 4 in Table 5.

7. Select (or not) a solution based on cost benefit analysis.

If only the risk due to functional loss is considered, then Solution 1 is preferred. This is because Solution 1 will cost $\$ 121,000$ and Solution 2 will cost $\$ 130,000$ as it shown in Table 4. However, when sustainability factors are considered, Solution 1 actually increases the overall expected risk and Solution 2 is preferred, as shown in Table 5. 


\begin{tabular}{lccc}
\hline Coupling resilience and sustainability & Existing & Solution 1 & Solution 2 \\
\hline & $\$$ & $\$$ & $\$$ \\
Capital cost of a/c & 0 & 100,000 & 100,000 \\
Capital cost of PV & 0 & 0 & 30,000 \\
Expected annual cost due to loss of reputation & 131,000 & 185,000 & 0 \\
Expected annual cost of carbon tax & 1,260 & 1,512 & 0 \\
Loss of function & 112,000 & 0 & 0 \\
Running cost of a/c & 18,000 & 21,600 & 0 \\
\hline Total & $\mathbf{2 6 2 , 2 6 0}$ & $\mathbf{3 0 8 , 0 0 0}$ & $\mathbf{1 3 0 , 0 0 0}$ \\
\hline
\end{tabular}

Table 5 Expected cost for the company over a 5-year period both resilience and sustainability are considered.

\section{$5 \quad$ DISCUSSION}

The example above illustrates how resilience and sustainability can be coupled and quantified within a risk framework that considers environmental, economic and social costs as well as the traditional cost associated with loss of function. For illustrative purposes, the example is simplified. In particular, more sophisticated probabilistic models could be considered - future costs could be discounted to reflect inflation and the net present value of money, costs such as carbon taxes could incorporate variation in taxation across years, and temperature predictions could utilize future-weather files based on climate modeling as proposed in (Cox RA (2015)). These, and many other more realistic assumptions can be supported within this framework, but are beyond the scope of this paper.

The simplified example only considers one element of resilience, namely resilience to heat waves. We note that it is common to partition a building into separate subsystems that can, for the most part, be treated independently. Most environmental assessment methods such as BREEAM and LEED, do so. It is straightforward to apply the same methodology to other subsytems and other elements of resilience, such as flooding. We also note that where two or more subsystems/elements interact, the methodology can easily integrate all risks and costs to allow practitioners to optimise their planned maintenance strategy.

The purpose of the simplified example is to illustrate how very different conclusions can be reached depending on whether only resilience, i.e. risk of loss of function, or resilience and sustainable are considered. In particular, it is interesting to note that while a traditional resilience analysis would consider a building to be perfectly resilient to an event if there is no loss of function, even a perfectly resilient building may not be sustainable, as the example above illustrates. Thus, when coupling both resilience and sustainability, changing the way a building's function is provisioned may be cost effective even when the building is considered perfectly resilient.

Our proposed CQRS method is generic and therefore accommodates variations in requirements for a maintenance management tool across user groups. For example, we do not fix the set of sustainability indicators, as is commonly done in BREEAM, LEED or DGNB. Rather, the methodology can support any indicators that a user community feels is appropriate. However, we also acknowledge that this strength is also a weakness in that it is often unclear how to map a particular indicator to a monetary value. It is also difficult to determine appropriate corresponding probabilities. 


\section{CONCLUSION}

The way a particular function of a building is provided may have significant repercussions beyond just resilience. To address this issue, this paper considers how to couple and quantify resilience and sustainable, where sustainability refers to not only environmental impact, but also economic and social impacts. We do so in the context of developing decision support tools for facilities managers. Within this context, we assume an economist's perspective, i.e. that facility managers are rational and base decisions on economic criteria. As such, we utilise a risk framework to quantify both resilience and sustainability. The risk framework allows us to couple resilience and sustainability so that the provision of a particular building can be investigated with consideration of functional, environmental, economic and possibly social dimensions.

The 7-step method of Coupling and Quantifying Resilience and Sustainability (CQRS) consists of (i) determining the resilience of the building to a disturbance, (ii) determining the costs associated with both the loss of building functionality and the building's current sustainability (iii) determining the corresponding probabilities associated with each cost (iv) determining the expected cost associated with the current resilience and sustainability of the building using risk analysis, (v) determining the capital and operational costs of each possible remedial solution, (vi) for each remedial solution, determining the expected cost associated with the proposed resilience and proposed sustainability of the building using risk analysis, and (vii) selecting a solution based on a cost benefit analysis.

The proposed CQRS method is illustrated with a simple example that highlights how very different conclusions can be drawn when considering only resilience or coupled resilience and sustainability. The methodology is generic allowing the method to be customized for different user communities. However, the example also illustrates the difficulty in deriving the costs and probabilities associated with particular indicators.

Further research is needed to translate this theoretical framework to a practical tool for practitioners and to evaluate the CQRS method in practice. In industries where risk analysis is routinely used, such as the life insurance industry, actuarial life tables provide probabilities of life expectancy. There is a need for similar tables to be developed at national and regional levels that allow practitioners to easily determine the probabilities necessary to complete the risk calculations needed to couple and quantify resilience and sustainability. Where practical, similar tables should also be developed to provide corresponding costs of, for example, possible future carbon taxes. Practitioners also need a user-friendly software suite that incorporates these tables and user provided data to calculate a building's sustainable resilience. 


\section{REFERENCES}

Anderies JM (2014), 'Embedding built environment in social-ecological systems: resiliencebased design principles', Building Research and Information, vol 42, no. 2, pp. 130-142.

Ballester F, Corella D, Pérez-Hoyos S, Sáez M, Hervás A (1997), 'Mortality as a function of temperature. A study in Valencia, Spain, 1991-1993'.

Baxter K1, Boisvert A, Lindberg C, Mackrael K(2010), 'Sustainability Primer', The natural step.

Beniston M, Stephenson DB, Christensen OB, Ferro CAT, Frei C, Goyette S, Halsnaes K, Holt T, Jylhä K, Koffi B, Palutikof J, Schöll R, Semmler T, Woth K, (2007), 'Future extreme events in European climate: an exploration of regional climate model projections', Climatic Change, pp.

81:71-95.

Biesbroek GR (2010), 'Europe adapts to climate change: Comparing National Adaptation Strategies', Global Environmental Change journal, pp. 440-450.

Bosher L (2014), 'Built-in resilience through disaster risk reduction: operational issues' Building Research and Information vol 42, no. 2, pp. 240-254.

Bosher L, Carrillo P, Dainty A, Glass J, Price A, (2007), 'Realising a resilient and sustainable built environment: towards a strategic agenda for the United Kingdom' Buildings and Civil Engineering.

Bossel, H (1999), 'Indicators for sustainability Development: Theory, Method, Appications', International Institut for sustainable development, Winnipeg.

Camilleri M, Jaques R, Isaacs N (2001), 'Impacts of climate change on building performance in New Zealand', Building Research \& Information, vol 29, no. 6, pp. 440-450.

Carpenter S, Walker B, Anderies JM, Abel N (2001), 'From Metaphor to Measurement:

Resilience of What to What?', Ecosystems, vol 4, pp. 765-781.

Cole RJ (1998), 'Emerging trends in building environmental assessment methods', Building Research and Information, vol 26, no. 1, pp. 3-16.

Cox RA, Nielsen SB (2014), 'Sustainable resilience in property maintenance encounting changing weather conditions', International Council for Research and Innovation in Building and Construction.

Cox RA, Drews M, Rode C, Nielsen SB (2014), 'Simple future weather files for estimating heating and cooling demand' Buildings and Environment, vol 83, pp. 104-114,.

de Wilde P, Tian W (2011), 'Towards probabilistic performance metrics for climate change impact studies', Energy and Buildings, pp. 3013-3018.

Detwiller P (2014), 'An essay on the notion of sustainability: oportunities and danger', CIB Facilities Management Conference 2014.

Ding G (2008), 'Sustainable construction - The role of environmental assessment tools', Journal of Environmental Management, vol 86, pp. 451-464, Sustainability Index.

Faber, M (2012), Engineering Decisions Under Uncertainty, Topics in Safety, Risk, Reliability and Quality. 
Folke C, Carpenter S, Elmqvist T, Gunderson L, Holling CS, Walker B (2002), 'Resilience and Sustainable Development: Building Adaptive Capacity in a World of Transformations', vol 31, http://www.ambio.kva.se.

Guan L, (2012), 'Energy use, indoor temperature and possible adaptation strategies for airconditioned office buildings in face of global warming', Building and Environment, pp. 8-19..

Hassler U, Kohler N (2014), 'Resilience in the built environment', Building Research and Informtion, vol 42, no. 2, pp. 119-129.

Holling C (1996), Engineering Resilience versus Ecological Resilience, Engineering within ecological constraints..

Jentsch MJ, Bahaj AS, James PAB (2008), 'Climate Change future proofing of buildings Generation and assessment of building simulation weather files', Energy and Buildings, vol 40, pp. 2148-2168.

Jones K (2014), 'Employing back casting principle for the formation of long term built asset mangement strategies- a theoretical approch', CIB Dacilities Management conference, International Council for Research and Innovation in Building and Construction.

Lomas K (2009), 'Resilience of naturally ventilated buildings to climate change: Advanced natural ventilation and hospital wards', Energy and Buildings,

Manyena S (2006), 'The concept of resilience revisited', Disasters, vol 30, no. 4, pp. 433-450.

McLellan et al., B, Zhang Q, Farzaneh H, Utama NA, Ishihara KN (2012), 'Resilience, Sustainability and Risk Management: A Focus on Energy', Challenges, vol 3, pp. 153-182.

Mills E (2003), 'Climate change, insurance and the buildings sector: technological synergisms between adaptation and mitigation', Building Research \& Information, pp. 257-277

Nelson DR, Adger WN, Brown K (2007), 'Adaptation to Environmental Change: Contributions of a Resilience Framework', Annual Review of Environment and Resources, vol 32, pp. 395-412.

Oeyen CF and Nielsen SB 2009, 'Management Tools for Sustainable and Adaptive Building Design' Architectural Management International Research and Practice.

Pimm S (1984), 'The complexity and stability of ecosystems', Nature, vol 307.

Snow M,, Prasad D (2011), 'Climate Change Adaptation for Building Designers: An Introduction'.

Tainter JA, Taylor T.G, (2014), 'Complexity, problem-solving, sustainability and resilience', Building Research and Information, vol 42, no. 2, pp. 168-181.

Vale L (2014), 'The politics of resilient cities: whose resilience and whose city', Building Research and Information, vol 42, no. 2, pp. 191-201.

Warren (2010), 'The facilities manager preparing for climate change related disaster', Facilities, vol 28, no. 11/12, pp. 502-5013. 


\section{Acknowledgments}

Thanks to Stine Tharhan, Inge Sørensen, Jeppe Zachariassen and their colleagues from Gentofte Property for financial and inspirational support for the research presented in this paper. We also would like to thank professor Per Anker Jensen for his advice 